\title{
The Effect of Temperature, Sulfonation, and PEG Addition on Physicochemical Characteristics of PVDF Membranes and Its Application on Hemodialysis Membrane
}

\author{
Retno Ariadi Lusiana $^{1^{*}}$, Ayub Indra ${ }^{1}$, Nor Basid Adiwibawa Prasetya ${ }^{1}$, Nurwarrohman Andre \\ Sasongko ${ }^{1}$, Parsaoran Siahaan ${ }^{1}$, Choiril Azmiyawati ${ }^{1}$, Nanik Wijayanti ${ }^{2}$, \\ Anugrah Ricky Wijaya ${ }^{3}$, and Mohd Hafiz Dzarfan Othman ${ }^{4}$ \\ ${ }^{1}$ Department of Chemistry, Faculty of Sciences and Mathematics, Diponegoro University, \\ Jl. Prof. H. Soedarto, S.H., Tembalang, Semarang 50275, Indonesia \\ ${ }^{2}$ Department of Chemistry, Faculty of Mathematics and Natural Sciences, Semarang State University, \\ Kampus Sekaran, Gunungpati, Semarang 50229, Indonesia \\ ${ }^{3}$ Department of Chemistry, Faculty of Mathematics and Natural Sciences, Universitas Negeri Malang, \\ Jl. Semarang No. 5 Malang 65145, East Java, Indonesia \\ ${ }^{4}$ Advanced Membrane Technology Research Centre (AMTEC), Faculty of Chemical and Energy Engineering, \\ Universiti Teknologi Malaysia, 81310 Skudai, Johor, Malaysia
}

\section{* Corresponding author: \\ email: retnolusiana@live.undip.ac.id}

Received: February 10, 2021

Accepted: June 23, 2021

DOI: $10.22146 /$ ijc. 63740

\begin{abstract}
Polyvinylidene fluoride (PVDF) membrane and its derivative have been investigated the permeation ability for creatinine and urea. The membrane was made by an inversion precipitation system in $\mathrm{N}, \mathrm{N}$-dimethyl acetamide (DMAc) and water as nonsolvents. In this study, the modification of PVDF membrane permeability with PEG additives, CBT variations, and sulfonation was successfully carried out. The membrane solidification process was carried out on three variations of the coagulation bath temperature (CBT): 30,45 , and $60^{\circ} \mathrm{C}$. Eight types of membranes were characterized by using FT-IR and TGA/DSC, followed by the analysis of their porosity, hydrophilicity, water uptake, swelling degree, tensile strength, and permeability of creatinine and urea. The FT-IR spectra indicate that PVDF modification has been successfully carried out. The porosity, hydrophilicity, water uptake, and swelling degree values increase with the modification of functional groups. Furthermore, improvements in creatinine and urea permeability and clearances are achieved by increasing CBT and sulfonation in the PVDF/PEG membrane. The presence of sulfonate groups improves the membrane permeability through the interaction of intermolecular hydrogen with water and dialysate compounds. The existence of PEG as a porogen enhanced membrane porosity. Creatinine and urea clearance values increase from $0.29-0.58$ and 6.38-20.63 $\mathrm{mg} / \mathrm{dL}$, respectively.
\end{abstract}

Keywords: PVDF membrane; inversion phase; CBT; physicochemical; permeation

\section{- INTRODUCTION}

In recent years, many people suffer chronic kidney disease. One of the methods to help the patient is the hemodialysis process. Currently, Membrane has been widely used as hemodialysis process to treat the patient who suffers a chronic kidney disease [1]. The membrane is a semipermeable thin layer that separates two phases (donor and acceptor). Typically, membranes are made from polymers such as polysulfone (PSF), polyethersulfone (PES), and PVDF, which have good hydrolytic stability, thermal stability, easy to generate, and permeable [2]. However, the permeability and biocompatibility of those materials must be enhanced to get the optimum separation [3].

The ideal hemodialysis membrane has a nonabsorbent character protein or cells, but can be permeable

Retno Ariadi Lusiana et al. 
to toxins in the blood, has high mechanical strength and stability in water, and biocompatible. A balance between hydrophilicity and hydrophobicity on the membrane surface dramatically influences the character membrane [4]. PVDF has been widely used as a membrane material due to advantages such as good mechanical strength, high thermal and chemical stability, anti-ultraviolet radiation, smooth surface, and no protein adsorption [5]. However, PVDF has several weaknesses: hydrophobic, low porosity, and less function group [6]. Therefore, it is crucial to enhance the character of PVDF membranes.

Zhang et al. studied the effect of PEG content on PVDF hollow fiber membranes [7]. The increasing PEG content in the membrane increases the porosity, hydrophilicity, tensile strength, and flux values. A study on the effect of coagulation bath temperature (CBT) for PVDF membranes suggested that the membrane with the highest thickness and porosity could be obtained at the temperature of $60{ }^{\circ} \mathrm{C}$ [8]. Zhang et al. had created PVDF/PEG hollow fiber membranes in various CBT: 15 , 30,45 , and $60^{\circ} \mathrm{C}$ [9]. Furthermore, the increase of CBT showed that the membrane has better elongation, porosity, and permeability [9]. In 2014, Fadaei et al. investigated the effect of PEG concentration and CBT variations $\left(25\right.$ and $\left.60^{\circ} \mathrm{C}\right)$ on the properties of the PVDF membrane. The increase in PEG and the CBT had enhanced porosity and flux values [10].

On the other hand, non-covalent interactions such as hydrogen bonds play a crucial role in many chemical processes to control the molecular structure, even mass transfer in the case of hemodialysis [2]. One way to enhance the functional group for PVDF membrane is the sulfonation process, giving an $\mathrm{SO}_{3} \mathrm{H}$ cluster in the PVDF structure. Furthermore, the sulfonation group helps the membrane make hydrogen bond interaction and improves hydrophilicity and mechanical strength $[2,11]$. This study aims to modify PVDF through the addition of PEG, sulfonation, and CBT variations in membrane manufacture. The addition of PEG and sulfonation has been known to increase porosity and membrane hydrophilicity. This is possible since the entry of the $-\mathrm{OH}$ and $-\mathrm{SO}_{4}$ groups is quite reactive into the PVDF backbone chain. Thus, water as a non-solvent is easy to diffuse into the material. CBT variations aim to control pore size in the mechanism of membrane formation. The pore size of the membrane determines the porosity, and the porosity, together with the hydrophilicity of membranes, could be adjusted to improve the membrane permeability.

\section{- EXPERIMENTAL SECTION}

\section{Materials}

Polyvinylidene fluoride (PVDF, $\mathrm{Mw}=60,000$ $\mathrm{g} / \mathrm{mol}$ ), polyethylene glycol (PEG, $\mathrm{Mw}=4,000 \mathrm{~g} / \mathrm{mol}$ ), N,N-Dimethyl Acetamide (DMAc), sulfuric acid (95$97 \%, \mathrm{Mw}=98.079 \mathrm{~g} / \mathrm{mol})$, sodium hydroxide $(\mathrm{Mw}=$ $39.997 \mathrm{~g} / \mathrm{mol})$, creatinine $(\mathrm{Mw}=113 \mathrm{~g} / \mathrm{mol})$, urea $(\mathrm{Mw}=$ $60 \mathrm{~g} / \mathrm{mol})$, picric acid $(\mathrm{Mw}=229.1 \mathrm{~g} / \mathrm{mol})$, 4-dimetylamine benzaldehyde (4-DAB) $(\mathrm{Mw}=149.19 \mathrm{~g} / \mathrm{mol})$, and ethanol (96\%) were purchased from Merck and without purification before being used.

\section{Instrumentation}

The functional groups of the membrane were determined using an FT-IR spectrophotometer (Perkin Elmer). Thermal stability membranes were analyzed using TGA Hitachi STA200RV instruments. The surface morphology and cross-section of the PVDF membrane were examined using scanning electron spectroscopy SEM of a JEOL JSM-6510LA instrument. Membrane hydrophilicity was measured by the sessile drop (OCA 25). Mechanical strength of membranes was measured using a tensile strength analyzer. The concentration of the transport sample was measured with a UV-Visible spectrophotometer at wavelengths of $486 \mathrm{~nm}$ for creatinine and $430 \mathrm{~nm}$ for urea.

\section{Procedure}

\section{Membrane preparation}

The membrane was prepared by the phase inversion method, with DMAc as a solvent and water as a non-solvent. Before being used, the PVDF crystals were dried at $100{ }^{\circ} \mathrm{C}$ for $1 \mathrm{~h}$. The membrane composition is summarized in Table 1. For membranes with the addition of PEG without sulfonation, the PEG powder was first dissolved in the DMAc solvent, followed by the addition of PVDF powder. To prepare the sulfonated membranes, 
Table 1. Dope solution composition and CBT condition of prepared membrane

\begin{tabular}{cccccc}
\hline $\begin{array}{c}\text { Membrane } \\
\text { Code }\end{array}$ & $\begin{array}{c}\text { PVDF } \\
(\mathrm{g})\end{array}$ & $\begin{array}{c}\text { PEG } \\
(\mathrm{g})\end{array}$ & $\begin{array}{c}\text { DMAc } \\
(\mathrm{g})\end{array}$ & $\begin{array}{c}\mathrm{H}_{2} \mathrm{SO}_{4} \\
(\mathrm{~mL})\end{array}$ & $\begin{array}{c}\mathrm{CBT} \\
\left({ }^{\circ} \mathrm{C}\right)\end{array}$ \\
\hline P & 3.75 & 0 & 21.25 & 0 & 30 \\
SP & 3.75 & 0 & 21.25 & 1 & 30 \\
PP30 & 3.75 & 0.75 & 20.125 & 0 & 30 \\
PP45 & 3.75 & 0.75 & 20.125 & 0 & 45 \\
PP60 & 3.75 & 0.75 & 20.125 & 0 & 60 \\
SPP30 & 3.75 & 0.75 & 20.125 & 1 & 30 \\
SPP45 & 3.75 & 0.75 & 20.125 & 1 & 45 \\
SPP60 & 3.75 & 0.75 & 20.125 & 1 & 60 \\
\hline
\end{tabular}

a concentrated $\mathrm{H}_{2} \mathrm{SO}_{4}$ and catalyst were put into the DMAc solvent. Then, the dried PVDF crystals were poured into a homogeneous mixture for $4 \mathrm{~h}$, followed by the addition of PEG additive powder. Next, all components were mixed in a dope solution at $60^{\circ} \mathrm{C}$ until the solution was homogeneous and formed a suspension for a total of $6 \mathrm{~h}$.

Furthermore, the dope solution was homogenized by ultrasonication for $15 \mathrm{~min}$ at $60^{\circ} \mathrm{C}$. The casting process was then carried out on a glass plate and soaked in a coagulant tub filled with water to form a thin film. Next, the membrane sheet was washed several times and then soaked for $24 \mathrm{~h}$ to vaporize the remaining solvent. Finally, the membrane was dried and stored for further research.

\section{FTIR analysis}

Analysis of functional groups membrane was conducted by using FT-IR spectrophotometer (Perkin Elmer). The thin membrane sheet was placed in the sample holder and measured at wavenumbers of $700-$ $4000 \mathrm{~cm}^{-1}$.

\section{TGA/DSC analysis}

The temperature was set in the temperature range of $30-900{ }^{\circ} \mathrm{C}$ with a heating rate of $5{ }^{\circ} \mathrm{C} / \mathrm{min}$. The membranes with a weight of 1.9-3.2 mg were placed in an aluminum crucible during heating rate. Thermal degradation is indicated by a decrease in sample weight that is automatically monitored. DSC data were obtained based on energy differences between the sample and the standard.

\section{Morphology studies}

The surface morphology and cross-section of the PVDF membrane were examined using EDX, installed in environmental SEM using the JEOL JSM-6510LA instrument. Thin membrane sheets were cut and glued to the sample holder, coated using platinum metal, then observed at an energy of $20 \mathrm{kV}$, with 1,000 and 1,500 magnification.

\section{Porosity measurement of membrane}

The membrane sample $(0.022 \mathrm{~g})$ was immersed in $10 \mathrm{~mL}$ of distilled water for $24 \mathrm{~h}$, coated with tissue to absorb water on the surface of the membrane, and weighed as the initial wet weight of the membrane ( $\mathrm{Ww}$ (g)). Furthermore, the membrane was dried in an oven with a temperature of $100{ }^{\circ} \mathrm{C}$ for $6 \mathrm{~h}$, cooled, and reweighed to measure the $\mathrm{Wd}(\mathrm{g})$ as the dry weight of the membrane. All steps are conducted in three repetitions. Percentage of membrane porosity was calculated through Eq. (1), where $\rho p=$ polymer density $\left(1.78 \mathrm{~g} / \mathrm{cm}^{3}\right)$; and $\rho \mathrm{w}=$ water density $\left(1.0 \mathrm{~g} / \mathrm{cm}^{3}\right)[1]$.

$\varepsilon=\frac{\mathrm{Ww}-\mathrm{Wd} / \rho \mathrm{w}}{(\mathrm{Ww}-\mathrm{Wd} / \rho \mathrm{w})+\mathrm{Wd} / \rho \mathrm{p}} \times 100 \%$

\section{Hydrophilicity (Water contact angle)}

Membrane hydrophilicity was measured by the sessile drop method, which illustrates the membrane's ability to absorb water that drips on its surface. Contact angles are formed between water droplets and membranes. Low contact angle values indicate the membrane has hydrophilic properties.

\section{Water uptake (WU) and swelling degree (SD)}

Water absorption is an important property on membranes to describe the membrane hydrophilicity and hydrophobicity associated with the degree of membrane porosity. To determine the WU and SD, 
$0.022 \mathrm{~g}$ of the membrane was immersed in water for $24 \mathrm{~h}$ and measured by weight and diameter both before and after immersion. The percentage values of WU and SD were calculated using Eq. (2) and (3), respectively. Wt represents the membrane weight after immersion (g), while Wo was membrane weight before immersion (g). $\mathrm{I}_{\mathrm{o}}$ and $\mathrm{I}_{\mathrm{t}}$ represent the diameter before and after immersion (in $\mathrm{cm}$ ), respectively.

$$
\begin{aligned}
& \mathrm{WU}=\frac{\mathrm{Wt}-\mathrm{Wo}}{\mathrm{Wo}} \times 100 \% \\
& \mathrm{SD}=\frac{\mathrm{It}}{\mathrm{Io}} \times 100 \%
\end{aligned}
$$

\section{Tensile strength}

Mechanical strength is one of the critical aspects of membrane dialysis. The $15 \times 3 \mathrm{~cm}$ of the synthesized membrane was immersed in distilled water until it expands, then pulled in a specific force until the membrane is broken (Tensile Strength Analyzer). Tensile strength was determined by the maximum load when the membrane was stretched with a certain force until it is torn, and the percentage of its elongation is based on the elongation of the membrane when it breaks. The tensile strength and percent elongation can be calculated using Eq. (4) and (5), where F represents the tensile strength $(\mathrm{N})$, A represents membrane cross-sectional area $\left(\mathrm{mm}^{2}\right)$, while $a$ and $b$ are the initial membrane length $(\mathrm{mm})$ and after breaking up $(\mathrm{mm})$, respectively.

Tensile strength $(\mathrm{MPa})=\frac{\mathrm{F}}{\mathrm{A}}$

Elongation at break $=\frac{\mathrm{b}-\mathrm{a}}{\mathrm{a}} \times 100 \%$

\section{Membrane permeability}

Membrane permeability was measured to know the ability of the membrane in transporting creatinine and urea. Permeation test was carried out using a set of tools with a membrane placed in the middle that separates the donor and acceptor parts. The source was filled with creatinine $1.5 \mathrm{mg} / \mathrm{dL}$ and urea $50 \mathrm{mg} / \mathrm{dL}$ as much as $50 \mathrm{~mL}$ in phosphate buffer media. The acceptor was filled with $50 \mathrm{~mL}$ phosphate buffer. The transport process was carried out for $6 \mathrm{~h}$ at room temperature. Every $1 \mathrm{~h}, 2 \mathrm{~mL}$ samples are taken from the source phase and the acceptor. The sample was complexed with picric acid for creatinine and
4-DAB for urea. It was then measured for its absorbance with a UV-Visible spectrophotometer at $486 \mathrm{~nm}$ (creatinine) and $430 \mathrm{~nm}$ (urea). The permeability of the membrane to the solute (clearance) is calculated by Eq. (6), where Co and Ct are the concentration of the source solution at $\mathrm{t}=0$ and $\mathrm{t}=6 \mathrm{~h}$.

Clearance $=\mathrm{Co}-\mathrm{Ct}$

\section{- RESULTS AND DISCUSSION}

\section{Membrane Characterization}

\section{Functional groups}

The interactions between PVDF with sulfuric acid and chitosan derivatives were performed using FT-IR. The success of the synthesis and modification processes for PVDF can be assessed from the suitability of the resulting functional groups. The FTIR spectra showed changes in the chemical composition of the PVDF membrane before and after the modification Fig. 1. The typical PVDF spectra are presented by the appearance of absorption at $766 \mathrm{~cm}^{-1}$ attributed to the bending vibration of $-\mathrm{CF}_{2}$. The absorption at the wavenumbers of 840 and $1374 \mathrm{~cm}^{-1}$, respectively, indicate the stretching and bending vibrations of the $-\mathrm{CH}_{2}$ group. The stretching vibrations of the $-\mathrm{CH}_{2}$ group are observed at 1402 and $2936 \mathrm{~cm}^{-1}$. The symmetrical stretching of the $-\mathrm{CF}_{2}$ group is indicated by the absorption at wavenumbers of 1071 and $1178 \mathrm{~cm}^{-1}$. The asymmetrical stretching vibration of the $-\mathrm{CF}_{2}$ group is observed at 1210 and $1279 \mathrm{~cm}^{-1}$. Furthermore, absorption at $878 \mathrm{~cm}^{-1}$ indicates the asymmetrical strain vibrations of the $\mathrm{C}-\mathrm{C}-\mathrm{C}$ group [2]. These data are supported by previous studies $[3,12]$. There is absorption with a widening peak in an area of about $3400 \mathrm{~cm}^{-1}$ which indicates the vibration of the $-\mathrm{OH}$ group, which comes from the diffusion of DMAc solvents with water during the solidification process [13]. It can be predicted that the $\mathrm{C}=\mathrm{O}$ group from the DMAc solvent attracts water molecules; so that there is an intermolecular hydrogen interaction between the $\mathrm{O}$ and $\mathrm{H}$ atoms. The coagulation process rapidly converts the dope solution into a membrane and causes $\mathrm{OH}$ to be trapped in the formed membrane. Sharp peaks in the area of $1739 \mathrm{~cm}^{-1}$ on the PVDF, PVDF/PEG, and Sulfonated-PVDF membranes 


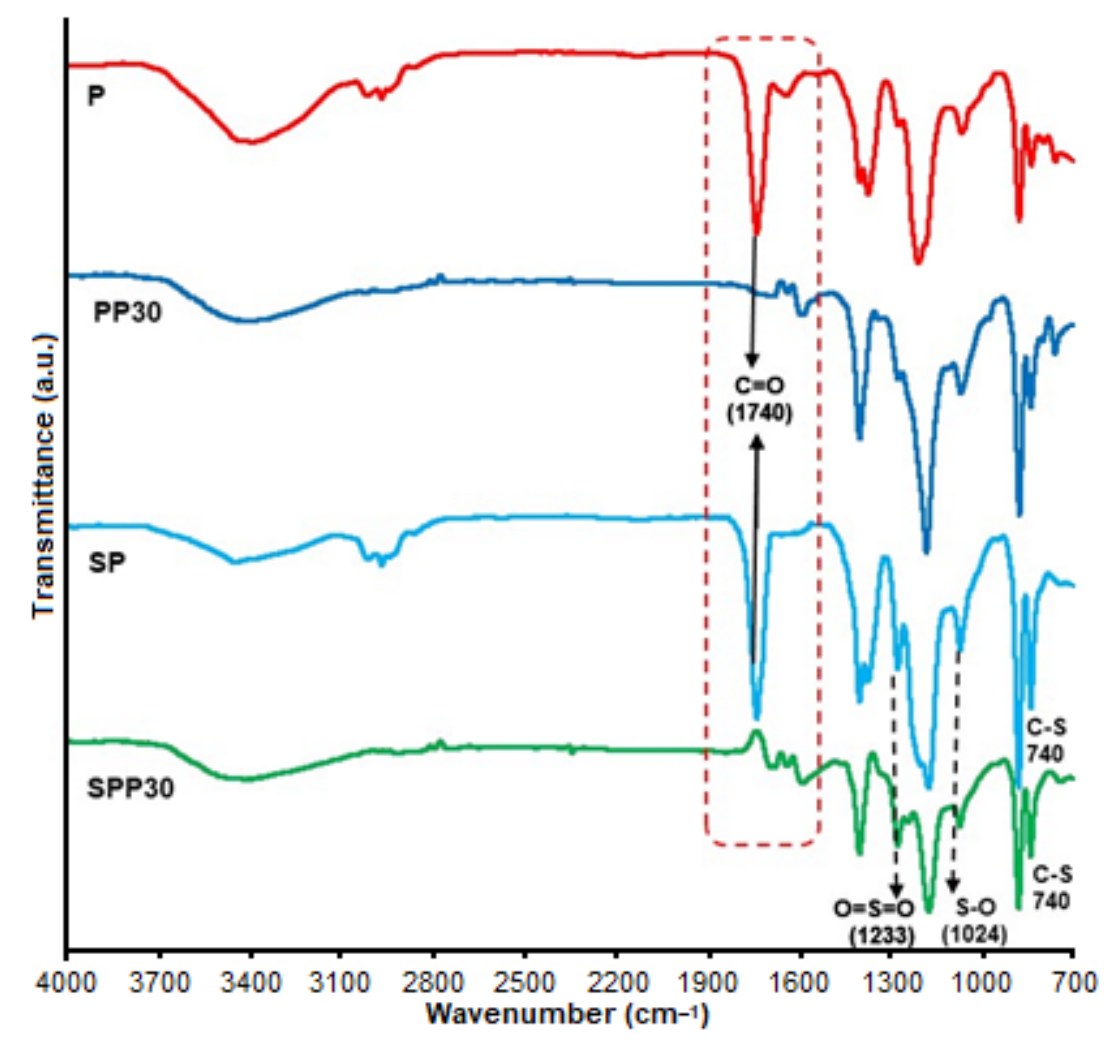

Fig 1. FTIR spectral profiles of (P) PVDF, (PP30) PVDF/PEG, (SP) SPVDF, (SPP30) SPVDF/PEG

show the vibrations of the $\mathrm{C}=\mathrm{O}$ group originating from the DMAc structure that has not completely evaporated during the membrane solidification process [11].

The addition of PEG in the structure of PVDF causing the emergence of widening absorption at $3440 \mathrm{~cm}^{-1}$ associated with the stretching vibration of $\mathrm{OH}$ groups originating from PEG [7] that can be seen in the spectra of PVDF/PEG and SPVDF/PEG membranes. The sulfonation process on the PVDF membrane resulted in the presence of $\mathrm{O}=\mathrm{S}=\mathrm{O}$, which is indicated by the absorption at the wavenumber of $1233 \mathrm{~cm}^{-1}$ [14] and symmetrical strain observed at $1040 \mathrm{~cm}^{-1}$. The reaction between PVDF and PEG takes place through the interaction of hydrogen. The electronegative $\mathrm{F}$ atoms form dipole interactions with $\mathrm{H}$ atoms from the PEG chain. Based on molecular weight stoichiometry calculations, every three PVDF monomers will bind to two PEG monomers. PVDF sulfonation takes place based on the unimolecular electrophilic substitution reaction (SE1) mechanism. The acidic atmosphere in the reaction causes the $\mathrm{H}$ atoms in the PVDF to be activated to become
$\mathrm{H}^{+}$and release. Then a negatively charged carbanion is formed in the PVDF chain, which acts as an intermediate for the reaction. This carbanion formation stage is slow, so it determines the rate of reaction. Furthermore, the negative carbanion group will attack the $-\mathrm{SO}_{3}{ }^{-}$group of sulfuric acid that is positively charged at the $\mathrm{S}$ atom. Because the reaction takes place in an acidic environment, the $-\mathrm{O}$ at the end of the $-\mathrm{SO}_{3}{ }^{-}$group can attract free-moving $\mathrm{H}^{+}$ions to form a sulfonate $\left(-\mathrm{SO}_{3} \mathrm{H}\right)$ group attached to the carbon atom in the PVDF chain. This stage takes place quickly so that it is not used as a stage determining reaction rate. The pathway of the PVDF modification reaction is presented in Fig. 2.

\section{Thermal stability}

TGA provides information related to the degradation of membrane material when the membrane is heated. DSC characterization aims to determine the glass transition temperature $(\mathrm{Tg})$ in various membranes and provide information about the level of hardness and flexibility in the polymer chain. The results of the TGA/DSC test for PVDF membranes before and after 


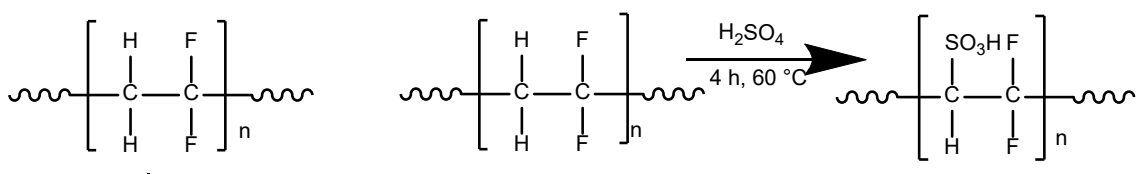

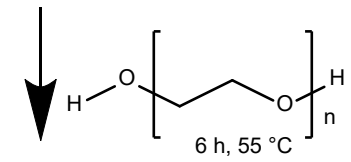

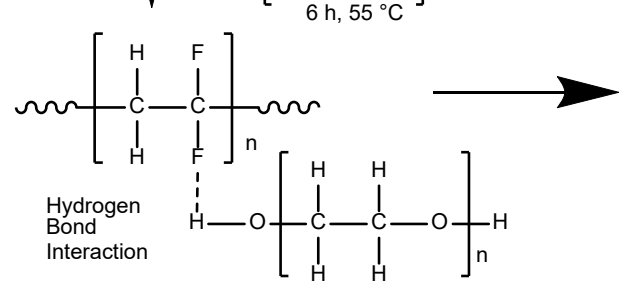

(a)

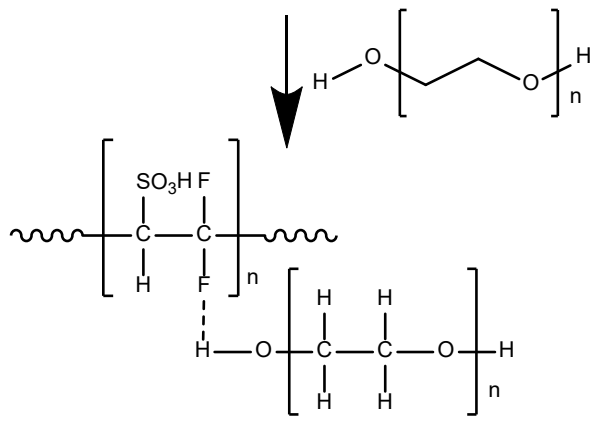

(b)

Fig 2. The synthetic pathway of PVDF modification: (a) mixing with PEG and (b) sulfonation reaction

modification are shown in Fig. 3 and Fig. 4. It can be seen that all membranes have thermograms that are similar to each other.

Before experiencing weight loss at the first stage, there was a slight decrease in weight at the temperatures of $150-160^{\circ} \mathrm{C}$ by approximately $0.1-0.5 \%$, which is related to the drying of DMAc solvents trapped in the membrane [9]. Weight reduction related to the thermal stability starts in the temperature range $420-470{ }^{\circ} \mathrm{C}$, where the PVDF, PVDF/PEG, and SPVDF membrane decreased by about $61.6,61.6$, and $62.9 \%$, respectively. The membranes are still stable and able to be used at a temperature less than $400^{\circ} \mathrm{C}$. At a temperature higher than $400^{\circ} \mathrm{C}$, the membrane starts to be damaged and melted. The decrease of weight in the temperature range is related to the decomposition process in the main polymer chain. PVDF undergoes $\mathrm{CH}$ bond breakdown and shows the presence of hydrogen and fluorine atoms which influence the formation of hydrogen fluoride gas (HF) [15]. The addition of PEG and

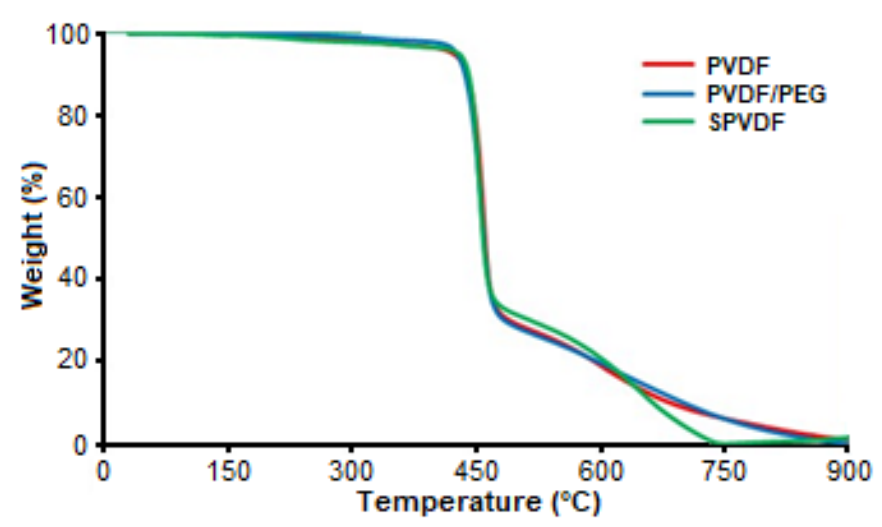

Fig 3. TGA Curve of PVDF and modified PVDF membranes
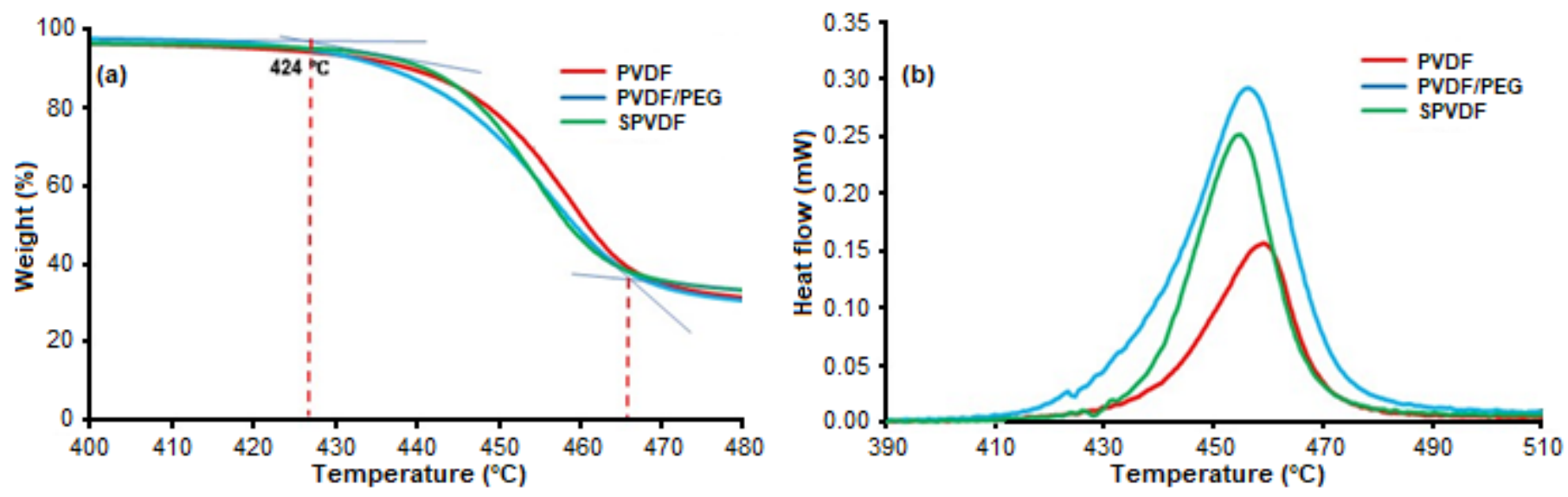

Fig 4. (a) TG curve and (b) DSC curve of PVDF and modified PVDF membranes 
sulfonation reactions slightly decrease the thermal stability of the membrane. Meanwhile, the decomposition occurs at a slightly lower temperature compared to pure PVDF membranes. The insertion of ethylene glycol and sulfonate groups causes the conformation of the chain to become softer and the structure to be less orderly, resulting in a decrease in thermal stability [16].

The addition of PEG and sulfonation reactions in the PVDF membrane slightly decreased the thermal stability of the membrane. Exothermic peaks in the temperature range of $400-500{ }^{\circ} \mathrm{C}$ indicate that the membrane has melted physically and chemically breaks the bonds in the main polymer chain. The reduction in stability is also related to the membrane structure where the lower Tg is more porous [12]. The entry of the ethylene glycol and sulfate structure into the PVDF binding structure affects the decrease in compacting and crystallinity in the polymer structure, thereby reducing the melting point of the PVDF membrane. The decrease in thermal stability due to the additives is caused by the disruption of hydrogen bonds between the polymer chains of the membrane matrix. The thermal stability of membranes with additives decreases because the additives interfere with hydrogen bonds in the polymer chain. The addition of additive material can reduce thermal stability due to the formation of pores that damage the integrity of the polymer matrix [17].

The TGA/DSC results are similar to the research conducted by H. Farrokhzad et al. and Nasirian et al. $[11,18]$. Similarly, in this study, PEG was able to enlarge the pore of the membrane. Large pores damage the integrity of the PVDF matrix. Furthermore, the thermal stability of the membrane decreases with the increase of pore size in the membrane. This is caused by the contraction of the polymer chain that occurs in membranes with closer pores.

\section{Morphology properties}

The surface morphology and cross-section of the PVDF membrane and its derivatives are shown in Fig. 5 and 6. All membranes have an asymmetrical structure consisting of a dense top layer and a porous sublayer. This is related to the membrane formation mechanism. During the solidification process, there is an interaction between the dope solution (PVDF/NMP) and the non-solvent (water). This meeting causes the immersion of the dope solution into the non-solvent. The NMP solvent penetrates the non-solvent and leaves the polymer solution (dope), and the non-solvent penetrates the polymer solution. This solvent exchange will cause the dope composition to change and then solidify to form a membrane.

The addition of PEG and sulfonation, a hydrophilic functional group, causes the dope solution to be less thermodynamically stable and follows an instantaneous separation mechanism resulting in a membrane with larger pores. In addition, the presence of hydrophilic additives in the dope solution increases the penetration of the non-solvent (water) to the dope solution and consequently an acceleration of the exchange rate between the solvent and non-solvent during the formation of the membrane in the coagulation bath [19]. The rapid exchange between solvent and non-solvent increases the rate of precipitation from the dope solution to the coagulation bath, which facilitates instantaneous separation and the formation of a porous membrane [20].

Increasing the temperature of CBT increases the rate of solvent to non-solvent exchange. As a result, the membrane solidification process takes place rapidly following the instantaneous liquid-liquid demixing
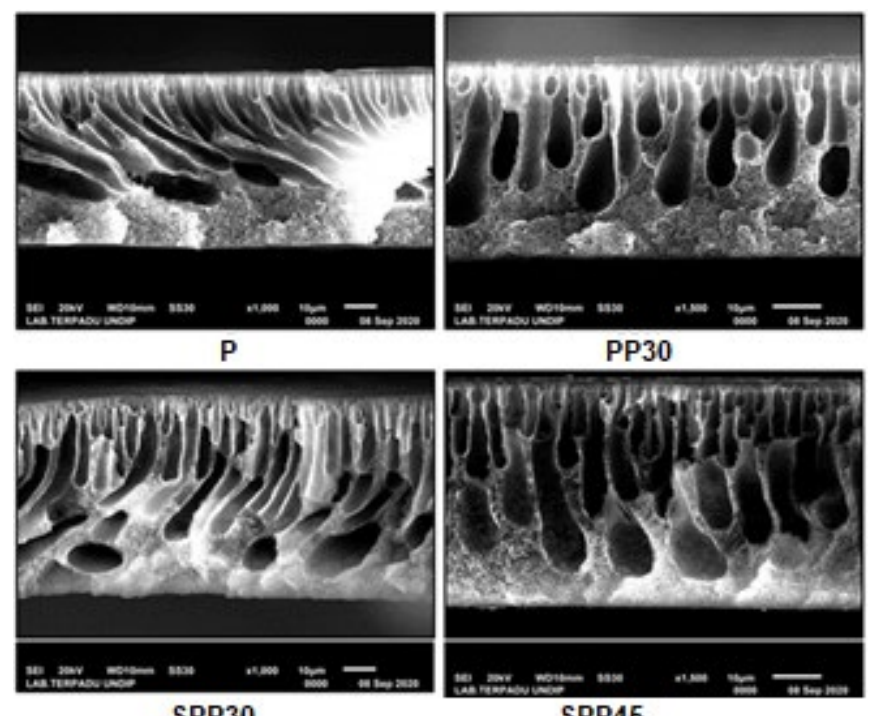

SPP30

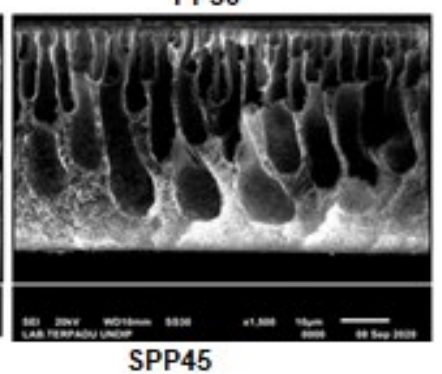

Fig 5. SEM cross-section image of membranes 


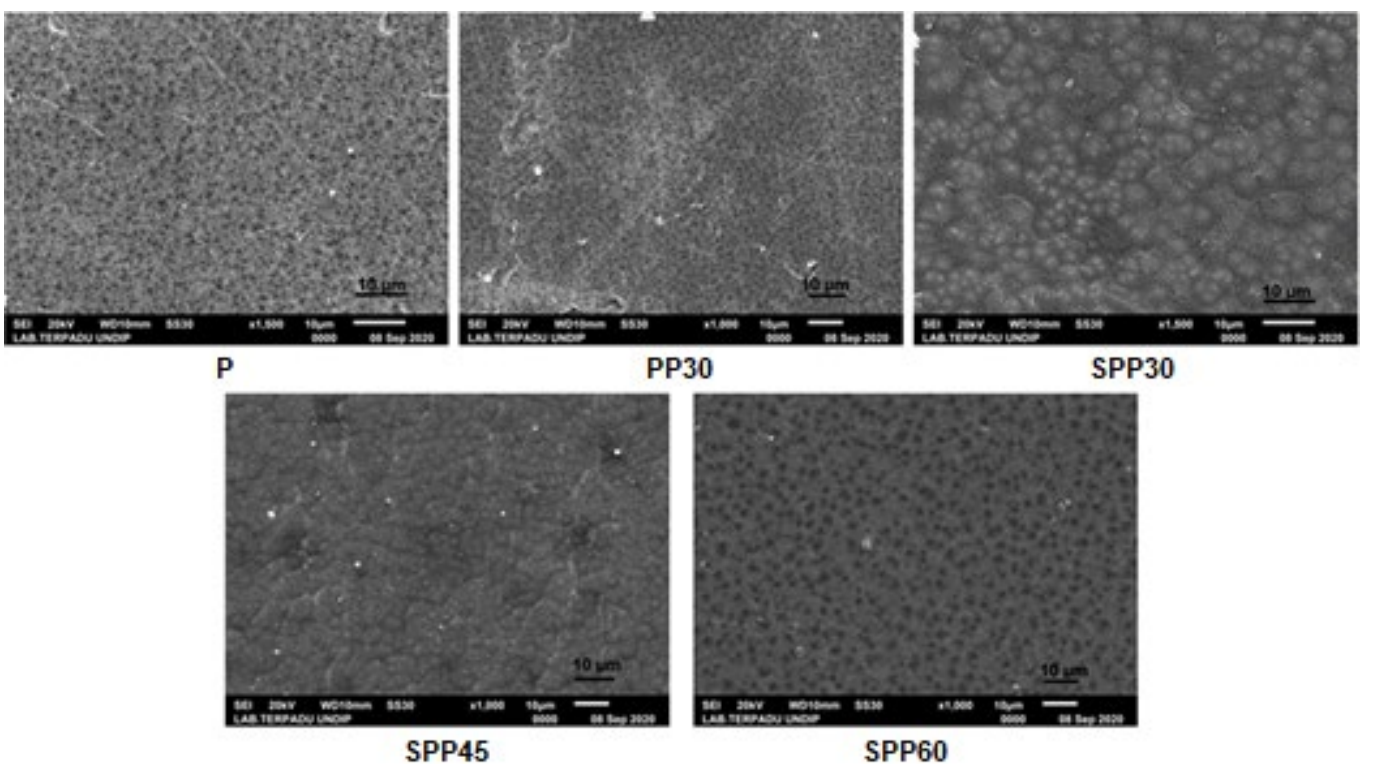

Fig 6. SEM surface image of membranes

mechanism, causing macrovoids growth in the sublayer and thinning in the top-layer membrane (Fig. 5). In general, the formation of macrovoids occurs under the conditions of rapid coagulation at higher temperatures. The effect of increasing CBT temperature is also observed on the membrane surface (Fig. 6). The pore size on the membrane surface increases, and the initially dense membrane structure expands to become wider with increasing temperature in the coagulation bath. The same results were obtained in the research of Zhang et al. [9], Chou et al. [21], and Amirilargani et al. [22] explained that increasing CBT increases diffusion between solvents and non-solvents in the phase inversion process so that the outer surface of the membrane gradually produces more cavities.

\section{Membrane porosity}

Modifications to PVDF caused the weight, thickness, and porosity of the membrane to decrease (Table 2). PEG compounds that are partially attached to the surface and pore of the membrane increased the solid content present in the dope solution [23]. Wang et al. explained that the solid phase formed in the coagulation process expands PVDF in the solvent [24]. The casting process makes the solvent evaporating into the air and leaving a shrinking polymer chain network. The coagulation process took place faster at high temperatures, caused fewer solvents evaporation, and decreased a smaller membrane shrinkage ratio. In addition, the fast separation was causing the exchange rate between the solvent and the non-solvent to increase so that the membrane formed becomes thicker. This is due to the outer layer of the membrane having the greatest contact area with the non-solvent. In addition, these phenomena cause the membrane to be thicker [18]. A similar result was also reported by Saljoughi et al. [17], in which the addition of PEG caused the increase of membrane thickness. PEG will fill the formed membrane matrix. Then, the diffusion process occurs between the solvent and the non-solvent. Additives and the solvent will dissolve in the non-solvent cavity to leave pores on the membrane [5]. Increasing CBT can

Table 2. Weight, thickness, and membrane porosity

\begin{tabular}{cccc}
\hline $\begin{array}{c}\text { Membrane } \\
\text { Code }\end{array}$ & $\begin{array}{c}\text { Weight } \\
(\mathrm{mg})\end{array}$ & $\begin{array}{c}\text { Thickness } \\
(\mu \mathrm{m})\end{array}$ & $\begin{array}{c}\text { Porosity } \\
(\%)\end{array}$ \\
\hline P & 7.3 & 2.54 & 66.48 \\
SP & 12.1 & 2.86 & 68.70 \\
PP30 & 11.8 & 2.88 & 63.59 \\
PP45 & 13.0 & 3.00 & 66.43 \\
PP60 & 15.1 & 3.16 & 80.84 \\
SPP30 & 16.6 & 3.52 & 77.04 \\
SPP45 & 17.3 & 3.88 & 79.01 \\
SPP60 & 19.4 & 3.94 & 82.94 \\
\hline
\end{tabular}


increase membrane porosity and cause membranes to have wider pore structures in the upper and lower layers of the membrane. Sulfonation caused an increase of electronegative $-\mathrm{OH}$ and $\mathrm{O}-\mathrm{S}=\mathrm{O}_{2}{ }^{-}$groups in the membrane. Note that the functional group is hydrophilic.

The trend of membrane porosity in this research is similar to the work conducted by Zhang et al. in [7], which shows that the increase of porosity caused by the increasing $\mathrm{CBT}$, and the thinning membrane skin structure as well as the widening membrane cellular structure causing the membrane porosity to increase. The increase in CBT produces more cavities on the outer surface of the membrane, which is the effect of PEG as a porogen. A discussion of membrane porosity has been shown in the morphology of the membranes. Membrane porosity refers to the empty space between spaces in the membrane. The high porosity can be interpreted that the membrane has a large empty space and affecting the membrane's ability to retain water increases. Penetration and flow of water will be easier with the increasing membrane porosity [24]. Sulfonation of the membrane can also generate a macrovoid which increases membrane porosity. According to Holda et al. [25], macrovoid growth because the attracting and floating force of the fluid flow during the casting process. Drag force plays a vital role in forming the final pore structure of the asymmetrical membrane. Sulfonation caused stronger polar-polar interactions between dope solutions and coagulants (water). Low drag force in the dope solution makes water easier to flow into the initial macrovoid and grow the macrovoid.

\section{Water contact angle (WCA)}

Fig. 7 shows that modification using PEG, sulfonation, and increasing the temperature of CBT decreased the contact angle of the membrane, which means increasing membrane hydrophilicity. When the dope solution is immersed in a coagulant bath in the coagulation process, a small amount of air is trapped in the layer where the solvent meets the non-solvent. Furthermore, this trapped air causes the membrane surface to solidify, resulting in a rough membrane surface. The inclusion of hydrophilic additives such as PEG and sulfates in the dope solution increases the ability to mix

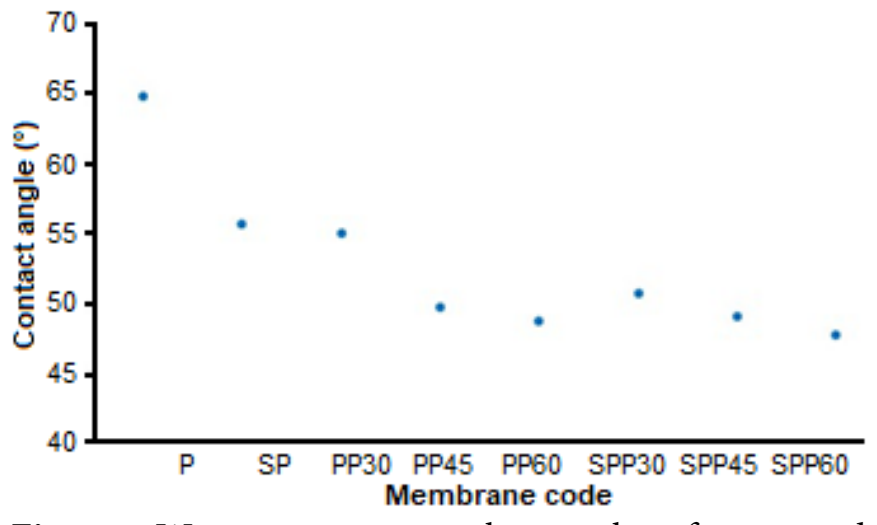

Fig 7. Water contact angle graph of prepared membranes

between polymer and non-solvents in the coagulation process. Additive compounds that can mix with nonsolvents in the coagulant bath will immediately diffuse out of the dope solution to produce a solid membrane. As the CBT temperature increases, the solvent diffusion process runs faster, less air is trapped, and the membrane's roughness decreases so that the contact angle decreases $[11,22]$.

The results of the hydrophilicity test and contact angle are in accordance with the research reported by Farrokhzad et al. [11] and Amirilargani et al. [22] that the addition of additives and increasing CBT can increase membrane hydrophilicity and decrease the contact angle of water on the membrane. The larger the macrovoid that is formed causes the water droplets that hit the membrane surface immediately drop into the holes in the macrovoid so that it reduces the water contact angle that occurs on the membrane surface. Based on the concept of polar-polar interactions, sulfonate groups on the membrane affect surface polarity and reduce the contact angle [25]. The increasing polarity on the sulfonated membrane indicates that the adsorption of water on the membrane surface is easier than the adsorption of water on the surface of the pure membrane. In addition, the presence of hydrophilic ionic groups in the PVDF backbone chain increases the hydrophilicity of the membrane surface and consequently decreases the contact angle [2].

\section{Dialysis Performance}

In this study, the transport process was carried out 
for $6 \mathrm{~h}$ with a membrane contact area of $4.96 \mathrm{~cm}^{2}$. The results of creatinine and urea transport are shown in Fig. 8. Creatinine clearance is increased by twice on the modified PVDF membrane. The clearance of PVDF membrane and SPVDF/PEG-CBT $60{ }^{\circ} \mathrm{C}$ are $0.29 \mathrm{mg} / \mathrm{dL}$ and $0.58 \mathrm{mg} / \mathrm{dL}$, respectively. Likewise, urea clearance increased from $6.38 \mathrm{mg} / \mathrm{dL}$ on pure PVDF membranes to $20.63 \mathrm{mg} / \mathrm{dL}$ on the $60^{\circ} \mathrm{C}$ SPVDF-PEG-CBT membranes. It can be concluded that the modification of PVDF membrane with PEG, the increasing of CBT, and sulfonation increased the ability of PVDF membrane in the process of creatinine and urea transport.

The PVDF membrane experienced structural changes because of the $-\mathrm{OH}$ and $-\mathrm{SO}_{3}{ }^{-}$functional groups (Fig. 2). The groups such as $-\mathrm{OH}$ and $-\mathrm{S}=\mathrm{O}$ that bond to the PVDF structure have a functional group with a high electronegativity to help the membrane bind urea and creatinine through hydrogen bonding. In addition, membrane hydrophilicity makes the membrane respond quickly to contact with water as media. According to Amiji [26], membrane permeability for creatinine and urea will increase proportionally with the increase in hydrophilic groups contained in the membrane. On the other hand, the value of membrane porosity also contributes to the membrane permeation ability. A porosity presents a lot of free space in the membrane that can be entered and passed through the donor phase to the acceptor phase. Increasing porosity enhanced the number of open cavities in the membrane. This condition will facilitate the flow of permeate through the membrane.
The addition of PEG and the increasing of CBT play an important role in forming wider macrovoid pores. Saljoughi et al. [17] explained that higher CBT intensively increased porosity and resulted in a wider structure in the upper and lower layers of the membrane, thereby increasing membrane permeability. Meanwhile, sulfonation increases the hydrophilic side of the membrane through the addition of the $-\mathrm{OH}$ and $\mathrm{S}=\mathrm{O}$ groups derived from sulfonates [19].

The increase in clearance value and transport percent after modification indicated that modification could increase membrane permeation in carrying out the transport of creatinine and urea molecules. The modification can increase hydrophilicity, porosity, and increase the number of hydrophilic sides on the membrane so that the membrane has a more remarkable ability to transfer dialysate into the acceptor phase. These results were obtained in the transport conditions without the push force. Meanwhile, the dialysis process, which is commonly used in the medical world, such as hemodialysis, is performed using a dialysis machine with a complete set of equipment. So that most patients experience a decrease in creatinine levels by $10-40 \%$ and a decrease in urea levels by $30-60 \%$ [27]. Based on the mechanical strength, porosity, and permeation ability of toxic compounds like urea and creatinine, it was found that the membrane from the study had a fairly good character [4]. It can be concluded that the modified PVDF membrane in this study has a fairly good ability in dialysis applications for the medical world.
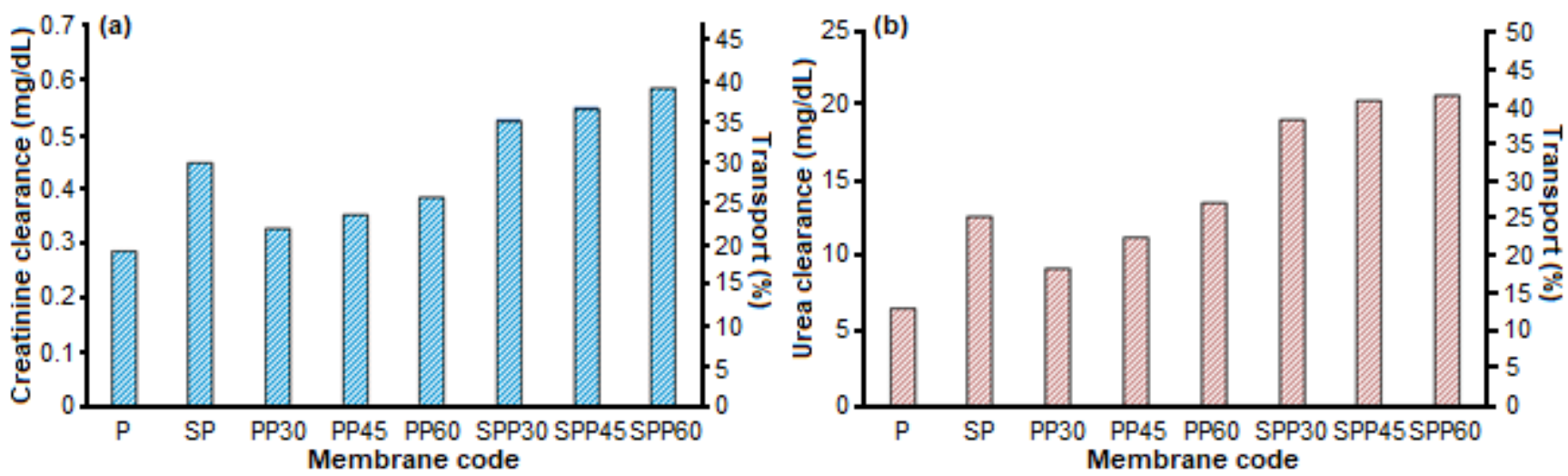

Fig 8. Comparison of permeability membranes towards (a) creatinine (b) urea 


\section{- CONCLUSION}

The modification of PVDF membrane permeability with PEG additives, CBT variations, and sulfonation was successfully carried out. Improvements in creatinine and urea permeability and clearances are achieved by increasing $\mathrm{CBT}$ and sulfonation in the PVDF/PEG membrane. The presence of sulfonate groups improves the membrane permeability through the interaction of intermolecular hydrogen with water and dialysate compounds. The existence of PEG as a porogen enhanced membrane porosity. Overall, the results show that the PVDF membrane modified with the addition of PEG, CBT variation, and sulfonation can be promoted as a hemodialysis membrane material.

\section{- ACKNOWLEDGMENTS}

The author is very thankful to the Directorate General of Higher Education, Government of Indonesia, for the funding through contract number 25757/UN7.6.1/PP/2020.

\section{- REFERENCES}

[1] Siahaan, P., Sasongko, N.A., Lusiana, R.A., Prasasty, V.D., and Martoprawiro, M.A., 2021, The Validation of molecular interaction among dimer chitosan with urea and creatinine using density functional theory: In application for hemodialysis membrane, Int. J. Biol. Macromol., 168, 339-349.

[2] Lusiana, R.A., Sangkota, V.D.A., Sasongko, N.A., Gunawan, G., Wijaya, A.R., Santosa, S.J., Siswanta, D., Mudasir, M., Abidin, M.N.Z., Mansur, S., and Othman, M.H.D., 2020, Permeability improvement of polyethersulfone-polyethylene glycol (PEG-PES) flat sheet type membranes by tripolyphosphatecrosslinked chitosan (TPP-CS) coating, Int. J. Biol. Macromol., 152, 633-644.

[3] Afsarian, Z., and Mansourpanah, Y., 2018, Surface and pore modification of tripolyphosphatecrosslinked chitosan/polyethersulfone composite nanofiltration membrane; Characterization and performance evaluation, Korean J. Chem. Eng., 35 (9), 1867-1877.

[4] Kaleekkal, N.J., Thanigaivelan, A., Tarun, M., and
Mohan, D., 2015, A functional PES membrane for hemodialysis - Preparation, characterization and biocompatibility, Chin. J. Chem. Eng., 23 (7), 12361244.

[5] Matsuda, M., Yamamoto, K., Yakushiji, T., Fukuda, M., Miyasaka, T., and Sakai, K., 2008, Nanotechnological evaluation of protein adsorption on dialysis membrane surface hydrophilized with polyvinylpyrrolidone, J. Membr. Sci., 310 (1), 219-228.

[6] Zhao, X., and Liu, C., 2016, Irreversible fouling control of PVDF ultrafiltration membrane with "fouled surface" for mimetic sewage treatment, RSC Adv., 6 (96), 94184-94192.

[7] Zhang, Q., Lu, X., dan Zhao, L., 2014, Preparation of polyvinylidene fluoride (PVDF) hollow fiber hemodialysis membranes, Membranes, 4 (1), 81-95.

[8] Wang, X., Zhang, L., Sun, D., An, Q., and Chen, H., 2008, Effect of coagulation bath temperature on formation mechanism of poly(vinylidene fluoride) membrane, J. Apply. Polym. Sci., 110 (3), 1656-1663.

[9] Zhang, H., Lu, X., Liu, Z., Ma, Z., Wu, S., Li, Z., Kong, X., Liu, J., and Wu, C., 2018, The unidirectional regulatory role of coagulation bath temperature on cross-section radius of the PVDF hollow-fiber membrane, J. Membr. Sci., 550, 9-17.

[10] Fadaei, A., Salimi, A., and Mirzataheri, M, 2014, Structural elucidation of morphology and performance of the PVDF/PEG membrane, $J$. Polym. Res., 21 (9), 545.

[11] Farrokhzad, H., Kikhavani, T., Monnaie, F., Ashrafizadeh, S.N., Koeckelberghs, G., Van Gerven, T., and Van der Bruggen, B., 2015, Novel composite cation exchange fi lms based on sulfonated PVDF for electromembrane separations, J. Membr. Sci., 474, 167-174.

[12] Nishiyama, T., Sumihara, T., Sato, E., and Horibe, H., 2017, Effect of solvents on the crystal formation of poly (vinylidene fluoride) film prepared by a spin-coating process, Polym. J., 49 (3), 319-325.

[13] Roy, K.J., Anjali, T.V., and Sujith, A., 2017, Asymmetric membranes based on poly(vinyl chloride): Effect of molecular weight of additive and 
solvent power on the morphology and performance, J. Mater. Sci., 52 (10), 5708-5725.

[14] Nikooe, N., and Saljoughi, E., 2017, Preparation and characterization of novel PVDF nanofiltration membranes with hydrophilic property for filtration of dye aqueous solution, Appl. Surf. Sci., 413, 41-49.

[15] de Jesus Silva, A.J., Contreras, M.M., Nascimento, C.R., and da Costa, M.F., 2020, Kinetics of thermal degradation and lifetime study of poly(vinylidene fluoride) (PVDF) subjected to bioethanol fuel accelerated aging, Heliyon, 6 (7), e04573.

[16] Hu, Y., Yan, L., and Yue, B, 2020, Sulfonation mechanism of polysulfone in concentrated sulfuric acid for proton exchange membrane fuel cell applications, ACS Omega, 5 (22), 13219-13223

[17] Saljoughi, Amirilargani, M., and Mohammadi, T., 2010, Effect of PEG additive and coagulation bath temperature on the morphology, permeability and thermal/chemical stability of asymmetric CA membranes, Desalination, 262 (1) 72-78.

[18] Nasirian, D., Salahshoori, I., Sadeghi, M., Rashidi, N., and Hassanzadeganroudsari, M., 2019, Investigation of the gas permeability properties from polysulfone/ polyethylene glycol composite membrane, Polym. Bull., 77 (10), 5529-5552.

[19] Mansur, S., Othman, M.H.D., Ismail, A.F., Sheikh Abdul Kadir, S.H., Goh, P.S., Hasbullah, H., Ng, B.C., Abdullah, M.S., Kamal, F., Abidin, M.N.Z., and Lusiana, R.A., 2019, Synthesis and characterisation of composite sulphonated polyurethane/polyether sulphone membrane for blood purification application, Mater. Sci. Eng., C, 99, 491-504.

[20] Boubakri, A., Bouchrit, R., Hafiane, A., and Bouguecha, S.A.T., 2015, Fluoride removal from aqueous solution by direct contact membrane distillation: Theoretical and experimental, Environ. Sci. Pollut. Res., 21 (17), 10493-10501.

[21] Syawaliah, Arahman, N., Mukramah, and Mulyati, S., 2017, Effects of PEG molecular weights on PVDF membrane for humic acid-fed ultrafiltration process, IOP Conf. Ser.: Mater. Sci. Eng., 180, 012129.

[22] Amirilargani, M., Saljoughi, E., Mohammadi, T., and Moghbeli, M.R., 2010, Effects of coagulation bath temperature and polyvinylpyrrolidone content on flat sheet asymmetric polyethersulfone membranes, Polym. Eng. Sci., 50 (5), 885-893.

[23] Lusiana, R.A., Sasongko, N.A., Sangkota, V.D.A., Prasetya, N.B.A., Siahaan, P., Kiswandono A.A., and Othman, M.H.D, In-Vitro study of polysulfone-polyethylene glycol/chitosan (PESPSf/Cs) membrane for urea and creatinine permeation, J. Kim. Sains Apl., 23 (8), 283-289.

[24] Marino, T., Russo, F., and Figoli, A., 2018, The formation of polyvinylidene fluoride membranes with tailored properties via vapour/non-solvent induced phase separation, Membranes, 8 (3), 71.

[25] Hołda, A.K., and Vankelecom, I.F.J., 2015, Understanding and guiding the phase inversion process for synthesis of solvent resistant nanofiltration membranes, J. Appl. Polym. Sci., 132 (27), 42130.

[26] Amiji, M.M., 1995, Permeability and blood compatibility properties of chitosan-poly(ethylene oxide) blend membranes for haemodialysis, Biomaterials, 16 (8), 593-599.

[27] Amin, N., Mahmood, R., Asad, M.J., Zafar, M., and Raja, A.M., 2014, Evaluating urea and creatinine levels in chronic renal failure pre and post dialysis, J. Cardiovasc. Dis., 2 (2), 182-185. 